\title{
Necessity of Electroencephalography in High-risk Brief Resolved Unexplained Event
}

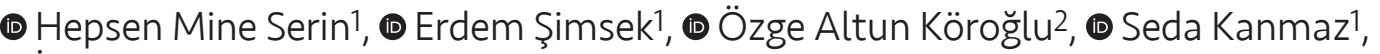

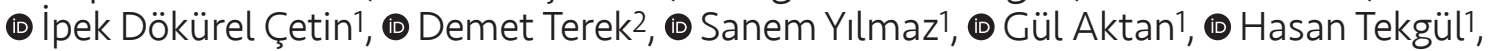 \\ (1) Nilgün Kültürsay², (1) Sarenur Gökben¹ \\ ${ }^{1}$ Ege University Faculty of Medicine, Department of Pediatrics, Division of Child Neurology, İzmir, Turkey \\ 2Ege University Faculty of Medicine, Department of Pediatrics, Division of Neonatology, İzmir, Turkey
}

\begin{abstract}
Aim: A brief resolved unexplained event (BRUE) is characterized by sudden alterations in an infant's breathing, color, tone, or responsiveness. The aim of this study was to evaluate the necessity of electroencephalography (EEG) in high-risk BRUE cases.

Materials and Methods: Fifty-one patients' cases were analyzed retrospectively. All of these patients were younger than 1 month so considered to be a high-risk group. The gestational week, the age of the patient, the duration of the event, the conditions related to the event, whether or not any intervention was needed, the type of intervention if done, if the event recurred, the number of recurrences, the state of consciousness during the event, respiratory pattern, muscle tone, sleeping position, suspicion of trauma, use of medication by mother and/ or baby and smoking exposure were evaluated in detail.

Results: The mean age of the patients was $15.74 \pm 14.96$ days, 31 (60.78\%) were male and $20(39.21 \%)$ were female. The mean gestational age was $37.64 \pm 2.35$ weeks. The neurological examinations of the patients were evaluated as normal. EEG was performed in 36 (70.58\%) of the 51 patients and only one patient had sharp waves in the left hemisphere central region. In 11 patients hospitalized with a preliminary diagnosis of BRUE, final diagnoses were found as congenital pyloric stenosis, dehydration, fetal myocarditis, patent ductus arteriosus, lower respiratory tract infection and gastroesophageal reflux.

Conclusion: It would be more appropriate to plan the tests to be carried out in the high-risk BRUE group by evaluating many factors such as recurrence of the event, family history, and neurological examination findings. As a result, even in the high-risk BRUE group, it would be cost effective to perform an EEG if only the clinical cues are strongly suggestive for the diagnosis of epilepsy.

Keywords: Brief resolved unexplained event, high risk, electroencephalography
\end{abstract}

\section{Introduction}

The scope of brief resolved unexplained event (BRUE) and apparent life-threatening event (ALTE) definitions overlap but they are not completely identical. The main difference is that for an event to be labeled BRUE, it should be unexplained after an appropriate history and physical examination (1). In May 2016, the American Academy of Pediatrics (APA) recommended the use of the term BRUE instead of the previously used ALTE by the issue of a guideline (2). The BRUE term underlines that it is a nonlife-threatening, temporary event with the lack of any clear reason. BRUE is defined as a sudden, short-term and resolved event in infants younger than one year of age. At 
least one of the following characteristics should be present in these attacks:

1. Cyanosis or pallor,

2. Absent, decreased or irregular breathing,

3. Marked change in muscle tone,

4. Altered level of responsiveness.

Sudden infant death syndrome (SIDS), seizures, central nervous system (CNS) abnormalities, cardiac problems and child abuse are some of the conditions that should be considered for the differential diagnosis of an infant brought in with a life threatening event and there is no consensus as to which diagnostic tests are required in these infants $(1,3,4)$. Patients who were defined as BRUE in the APA guideline were divided into low and highrisk groups according to history and physical examination findings. Patients in the low risk BRUE group should have the following characteristics:

1. Age must be greater than two months,

2. Gestational age $\geq 32$ weeks and post-conceptional age $\geq 45$ weeks,

3. First BRUE,

4. Duration of event $<1$ minute,

5. No cardiopulmonary resuscitation required by trained medical personnel,

6. No concerning historical features or physical examination findings.

In the lower-risk group, clinicians are advised to inform the family, also they may briefly monitor oxygen saturation with pulse oximetry, and may obtain an electrocardiography. In addition, routine electroencephalography (EEG) is not advised in this lower-risk group (2). According to the APA guideline, high-risk BRUE is a diagnosis based on history and physical examination, and requires further investigation (2).

The aim of this study was to evaluate the necessity of EEG in high-risk BRUE cases.

\section{Materials and Methods}

Patient records of the Neonatal Intensive Care Unit at Ege University Medical Faculty were retrospectively analyzed. Those patients who were followed up with a diagnosis of BRUE between January 2017 and January 2018 were included in the study. All of the patients were younger than 1 month so considered to be in the high-risk group. The gestational week, the age of the patient, the duration of the event $(<1$ minute, 1-5 minutes, $>5$ minutes), the conditions related to the event, whether or not any intervention was needed, the type of intervention if done, if the event recurred, the number of recurrences, the state of consciousness during the event, respiratory pattern, muscle tone, sleeping position, suspicion of trauma, use of medication by the mother and/or baby and smoking exposure were evaluated in detail. The neurological evaluation of patients, EEG, cranial ultrasonography (USG), cranial magnetic resonance imaging (MRI) and final diagnosis were recorded. This study was approved by the Ege University Local Ethics Committee under the approval number: 18-9.1/35 and was conducted in accordance with the principles of the Declaration of Helsinki. All of the parents of the patients gave their informed consent prior to their child's inclusion in the study.

\section{Statistical Analysis}

Statistical analyses were conducted using SPSS 22.0 for Windows (SPSS Inc., Chicago, IL). Descriptive analysis was used and variables was given as frequency and percentage.

\section{Results}

A total of 51 patients who were followed-up with the diagnosis of BRUE were included in this study. The mean age of these patients was $15.74 \pm 14.96$ days, 31 $(60.78 \%)$ were male and 20 (39.21\%) were female. The mean gestational age was $37.64 \pm 2.35$ weeks. The duration of the event was $<1$ minute for 33 (64.70\%) patients, 1- 5 minutes for 16 (31.37\%) patients and $>5$ minutes for 2 (3.92\%) patients. The event occurred in the postprandial period in 27 patients. It was associated with vomiting in 9 patients and crying in 2 patients. In two patients, the event occurred during sleep and 15 patients did not have any associated event. Ten patients were intervened with via tactile stimuli and no other intervention was performed. Eleven of the patients had a recurrence in the first 24 hours. A change in responsiveness was observed in four patients. Forty patients were in a supine position at the time of the incident. The lying position was not known in 11 patients. Fourteen patients had apnea, but no change of breathing pattern was reported in the remaining patients. According to the information obtained from the families, 14 patients had decreased muscle tone and 9 cases had increased muscle tone during the event. None of the patients had a history or suspicion of trauma. Four patients had a history of anti-reflux treatment (sodium alginate and magnesium alginate) and one patient had phenobarbital use. While there was no history of maternal drug use, two patients had a history of smoking in both parents. None of the patients had a family history of epilepsy. Neurological examination of the patients was performed by pediatric 
neurologists and all were evaluated as normal. Cranial USC was performed in 44 patients and abnormalities were detected in 3 patients (germinal matrix hemorrhage grade 1 , cavum septum pellucidum and slit ventricle). The patient with slit ventricles in cranial sonography underwent cranial MRI which was found to be normal. EEG was performed in $36(70.58 \%)$ of the 51 patients and only one patient had sharp waves in the left hemisphere central region. This patient was on phenobarbital treatment which was started at another hospital due to the suspicion of seizure. Cranial MRI was normal. Phenobarbital treatment was discontinued because the patient was seizure-free. This patient did not have recurrences. Follow-up and EEG control were found to be normal.

In 11 patients hospitalized with a preliminary diagnosis of BRUE, final diagnoses were found as congenital pyloric stenosis (1 patient), dehydration (1 patient), fetal myocarditis (1 patient), patent ductus arteriosus (1 patient), lower respiratory tract infection ( 3 patients) and gastroesophageal reflux (4 patients).

Clinical features of patients are summarized in Table I.

\section{Discussion}

The existence of a life-threatening event in infancy often requires extensive investigations. However, even after extensive research, approximately $40 \%$ of these events remain unexplained. Therefore, a detailed history and physical examination are considered as the most accurate diagnostic methods before the implementation of expensive investigations (3).

The mean age of the patients was $15.74 \pm 14.96$ days and the mean gestational week was $37.64 \pm 2.35$ weeks. We evaluated all of our patients to be in the high-risk group because they were all younger than 2 months of age.

ALTE/BRUE may be the first sign of epileptic seizure in children. Neurological assessment, including neuroimaging and EEG, is often obtained because of concerns that seizures or other CNS pathologies may cause a life-threatening event. However, in the studies conducted, it was observed that the risk of long-term epilepsy ranged between 3\% and $11 \%$ in patients with ALTE $(4,5)$.

Bonkowsky et al. (4) retrospectively evaluated 471 patients hospitalized after a life-threatening event and found that only $3 \%$ of these patients were diagnosed with epilepsy. In $71 \%$ of the patients who developed epilepsy, the second incident occurred within one month of the first event. EEG was performed in 156 (33\%) of the patients and only $6(1.3 \%)$ patients had abnormalities. While two of these patients had post neonatal epilepsy, 11 patients with post neonatal epilepsy had normal EEGs at the time of the first event. The sensitivity of EEG in the prediction of post neonatal epilepsy was low (13\%). In addition, it was emphasized that the neurological evaluation performed during ALTE had a low value in predicting post neonatal epilepsy. In our study, a recurrence of episodes occurred in eight patients within the first 24 hours, while none of the patients had recurrences in the following one month. EEG was abnormal in only one (2.7\%) of 36 patients.

In another study, 172 patients with recurrent ALTE were evaluated. Seventeen patients with normal interictal EEG's had clinical features suggesting focal epilepsy. All patients underwent continuous monitoring for EEG and other physiological parameters (breathing, electrocardiogram, oxygen saturation). Six patients had EEC abnormalities preceding physiological changes consistent with ALTE (6).

Nunes et al. (7) presented six children displaying a first episode similar to ALTE who were ultimately diagnosed with epilepsy. The neurological examinations and neuroimaging findings of these patients were found to be abnormal. These patients also had family history of epilepsy and SID.

Tirosh and Jaffe (8) evaluated 46 patients with ALTE and found that seven patients had CNS disorders such as convulsion, developmental retardation, intraventricular hemorrhage, hydrocephalus and corpus callosum agenesis. However, these patients had recurrent episodes of ALTE, episodes requiring resuscitation, abnormal neurological examination findings and a family history of epilepsy. In addition, the first EEG was normal in some patients and EEG abnormality was only detected in follow-up EEGs. The patients included in our study did not have a family history of epilepsy and their neurological examinations and neuroimaging were found to be normal. Eight patients had recurrent episodes but none of the patients required resuscitation.

In another study evaluating the contribution of EEG to ALTE, EEG was performed in 15 of 47 patients with ALTE and abnormalities were found in two cases. As a result, the authors reported that EEG had low additional value (13\%) in ALTE (9). Genizi et al. (3) found that, of the 15 patients diagnosed with clinical seizures, only one had abnormal interictal EEG. In our study, EEG was abnormal in only one case.

We did not find any signs suggesting trauma or child abuse in any of our patients. All had normal neurological examinations, and no family history of epilepsy or SID. One patient had an abnormal EEG and phenobarbital treatment 


\begin{tabular}{|c|c|c|c|c|c|c|}
\hline Patient no & $\begin{array}{l}\text { Sex/age } \\
\text { (days) }\end{array}$ & $\begin{array}{l}\text { Gestational } \\
\text { week }\end{array}$ & Recurrence & EEG & TFUSG & Final diagnosis \\
\hline 1 & $M / 23$ & 41 & & Normal & Normal & \\
\hline 2 & $M / 6$ & 40 & 1 & Normal & Abnormal & \\
\hline 3 & $M / 12$ & 37 & & ND & Normal & Lower respiratory tract infection \\
\hline 4 & $M / 5$ & 38 & & Normal & Normal & \\
\hline 5 & $M / 24$ & 35 & & ND & Normal & \\
\hline 6 & $M / 21$ & 39 & & Normal & Normal & Congenital pyloric stenosis \\
\hline 7 & $M / 15$ & 39 & & ND & Normal & \\
\hline 8 & $M / 31$ & 32 & & Normal & Normal & \\
\hline 9 & $M / 3$ & 38 & & ND & ND & Dehydration \\
\hline 10 & $\mathrm{~F} / 1$ & 36 & & ND & Normal & Gastroesophageal reflux disease \\
\hline 11 & $F / 2$ & 39 & & ND & ND & \\
\hline 12 & $M / 1$ & 38 & & Normal & Normal & \\
\hline 13 & $M / 2$ & 34 & & Normal & Normal & \\
\hline 14 & $F / 1$ & 37 & & Normal & Normal & \\
\hline 15 & $M / 2$ & 39 & 1 & ND & Normal & \\
\hline 16 & $M / 8$ & 40 & & ND & ND & \\
\hline 17 & $M / 59$ & 33 & & Normal & Normal & Patent ductus arteriosus \\
\hline 18 & $F / 1$ & 41 & 1 & ND & Normal & \\
\hline 19 & $\mathrm{~F} / 17$ & 40 & & Normal & Normal & \\
\hline 20 & $M / 24$ & 39 & & ND & ND & Gastroesophageal reflux disease \\
\hline 21 & $F / 8$ & 37 & 1 & ND & ND & \\
\hline 22 & $F / 2$ & 40 & & Normal & Normal & \\
\hline 23 & $M / 25$ & 38 & 2 & Abnormal & Normal & \\
\hline 24 & $M / 10$ & 38 & & Normal & Normal & \\
\hline 25 & $K / 53$ & 33 & 3 & Normal & Normal & Gastroesophageal reflux disease \\
\hline 26 & $K / 53$ & 33 & 3 & Normal & Normal & Gastroesophageal reflux disease \\
\hline 27 & $M / 12$ & 37 & 2 & Normal & Normal & \\
\hline 28 & $F / 18$ & 37 & & Normal & Normal & Lower respiratory tract infection \\
\hline 29 & $F / 52$ & 30 & 2 & Normal & Normal & \\
\hline 30 & $M / 20$ & 36 & 2 & Normal & Normal & Lower respiratory tract infection \\
\hline 31 & $M / 3$ & 40 & & Normal & Normal & \\
\hline 32 & $F / 15$ & 38 & 2 & Normal & Normal & \\
\hline 33 & $M / 28$ & 38 & & Normal & Normal & \\
\hline 34 & $F / 2$ & 40 & & ND & Normal & \\
\hline 35 & $M / 11$ & 39 & & Normal & Normal & \\
\hline 36 & M/37 & 36 & & ND & ND & \\
\hline 37 & $F / 37$ & 35 & & Normal & Abnormal & \\
\hline 38 & $F / 27$ & 39 & & Normal & Normal & \\
\hline 39 & $M / 13$ & 38 & & Normal & Normal & \\
\hline
\end{tabular}




\begin{tabular}{|c|c|c|c|c|c|c|}
\hline Patient no & $\begin{array}{l}\text { Sex/age } \\
\text { (days) }\end{array}$ & $\begin{array}{l}\text { Gestational } \\
\text { week }\end{array}$ & Recurrence & EEG & TFUSG & Final diagnosis \\
\hline 40 & $\mathrm{~F} / 10$ & 39 & & ND & Normal & \\
\hline 41 & $M / 6$ & 38 & & Normal & Normal & \\
\hline 42 & $M / 14$ & 39 & & ND & ND & \\
\hline 43 & $M / 8$ & 37 & & Normal & Normal & \\
\hline 44 & $M / 2$ & 39 & & Normal & Normal & \\
\hline 45 & $F / 12$ & 38 & & Normal & Normal & \\
\hline 46 & $M / 25$ & 37 & & ND & Normal & \\
\hline 47 & $\mathrm{~F} / 7$ & 40 & & Normal & Normal & \\
\hline 48 & $\mathrm{M} / 3$ & 38 & & Normal & Normal & \\
\hline 49 & $F / 2$ & 40 & & Normal & Normal & \\
\hline 50 & $\mathrm{~F} / 11$ & 38 & & Normal & Normal & Fetal myocarditis \\
\hline 51 & $\mathrm{M} / 19$ & 38 & & Normal & Abnormal & \\
\hline
\end{tabular}

${ }^{*}$ ND: Not done, EEG: Electroencephalography, TFUSG: Transfontanelle ultrasonography

was started at another hospital due to the suspicion of seizure. She had no recurrence during follow-up and phenobarbital was tapered within one month. Her control EEG obtained 3 months later was normal.

McGovern and Smith (5) reviewed eight studies, including 643 infants (0-13 months) in terms of the etiology of ALTE. The most common final diagnoses were gastroesophageal reflux $(31 \%)$, seizure $(11 \%)$ and lower respiratory tract infection (8\%). $23 \%$ of the patients were not diagnosed (reason unknown). In this review, 5 deaths were reported in total and all of them occurred in infants with an underlying medical problem. In 11 (21.5\%) of our patients, a detectable cause was found and the most common final diagnosis was gastroesophageal reflux (4 patients). This was followed by lower respiratory tract infection (3 patients), congenital pyloric stenosis (1 patient), dehydration (1 patient), fetal myocarditis (1 patient) and patent ductus arteriosus (1 patient).

Since most patients who develop post neonatal epilepsy will have a second episode within one month, delaying the initiation of antiepileptic drug will avoid potential morbidities associated with unnecessary exposure to these drugs (4). In addition, studies have shown that even if a patient is finally diagnosed with seizures/epilepsy, there is no difference in seizure remission between initiating treatment after the first seizure or the second seizure $(10,11)$.

The American neurology academy recommends EEC after the first afebrile seizure, but its sensitivity after the first BRUE attack is quite low. Normal EEG cannot exclude seizures and an abnormal EEG is quite inadequate to predict epilepsy development (2).

\section{Study Limitations}

The retrospective nature of this study is the limitation of the study.

\section{Conclusion}

The risk of developing epilepsy after BRUE is unlikely to be determined by EEG alone. It would be more appropriate to plan the tests to be carried out by evaluating many factors such as recurrence of the event in the high-risk BRUE group, family history, and neurological examination findings. As a result, even in the high-risk BRUE group, it would be cost feasible to acquire an EEG if only the clinical cues are strongly suggestive for the diagnosis of epilepsy.

\section{Ethics}

Ethics Committee Approval: This study was approved by the Ege University Faculty of Medicine Clinical Research Ethics Committee (approval number: 18-9.1/35).

Informed Consent: All of the parents of the patients gave their informed consent prior to their child's inclusion in the study.

Peer-review: Externally peer-reviewed.

\section{Authorship Contributions}

Surgical and Medical Practices: H.M.S., S.K., E.Ş., Concept: H.M.S., S.Y., G.A., D.T., Design: H.M.S., Ö.A.K., H.T., 
Data Collection or Processing: H.M.S., I.D.Ç., E.Ş., D.T., S.K., Analysis or Interpretation: H.M.S., N.K., S.G., Literature Search: H.M.S., E.Ş., S.K., S.Y., Writing: H.M.S., S.G., E.Ş.

Conflict of Interest: The authors have stated that they had no interests which might be perceived as posing a conflict.

Financial Disclosure: The authors declared that this study received no financial support.

\section{References}

1. Brand DA, Fazzari MJ. Risk of death in infants who have experienced a brief unexplained event: a meta-analysis. J Pediatr 2018;197:63-7.

2. Tieder JS, Bonkowsky IL, Etzel RA, et al. Clinical Practice Guideline: brief resolved unexplained events (formerly apparent life-threatening events) and evaluation of lower-risk infants. Pediatrics 2016;137:e20160590.

3. Genizi J, Pillar G, Ravid S, Shahar E. Apparent life-threatening events: neurological correlates and the mandatory work-up. J Child Neurol 2008; 23:1305-7.

4. Bonkowsky IL, Guenther E, Filloux FM, Srivastava R. Death, child abuse, and adverse neurological outcome of infants after an apparentlifethreatening event. Pediatrics 2008;122:125-31.
5. McGovern MC, Smith MB. Causes of apparent life threatening events in infants: a systematic review. Arch Dis Child 2004;89:1043-8.

6. Hewertson I, Poets CF, Samuels MP, Boyd SG, Neville BC, Southall DP. Epileptic seizure-induced hypoxemia in infants with apparent life-threatening events. Pediatrics 1994;94:14856.

7. Nunes ML, Appel CC, da Costa IC. Apparent life-threatening episodes as the first manifestation of epilepsy. Clin Pediatr (Phila) 2003;42:19-22.

8. Tirosh E, Jaffe M. Apparent life-threatening event: a neurologic perspective. I Child Neurol 1995; 10:216-8.

9. Fuger $M$, Merdariu $D$, Maurey $H$, Kaminska $A$, Chéron $G$ Relevance of electroencephalography in infants presenting to an emergency department who have had an apparent lifethreatening event. Arch Pediatr 2014;21:1206-12.

10. Leone MA, Solari A, Beghi E. First Seizure Trial (FIRST) Group. Treatment of the first tonic-clonic seizure does not affect longterm remission of epilepsy. Neurology 2006;67:2227-9.

11. Musicco M, Beghi E, Solari A, Viani F. First Seizure Trial (FIRST) Group. Treatment of first tonic-clonic seizure does not improve the prognosis of epilepsy. Neurology 1997;49:991-8. 